\section{WASHINGTON DC}

Many chemists might not know it, but the organization that represents them in the United States is fighting to limit their free access to chemical information. The American Chemical Society says that a new publicly funded database of molecules threatens its own fee-based Chemical Abstracts Service (CAS), and it is lobbying politicians to restrict the free version. But it is having trouble convincing members that this is in their interests.

CAS is part of many chemists' daily routine. The service is a massive registry of chemicals with their structures and properties, as well as links to related publications and patents.

Depending on their size, chemistry departments and companies pay from a few thousand to more than a hundred thousand dollars for a year's access to the database.

Chemists have had no alternative. A journal search will not find a chemical structure, so the database is the only way to find previously reported molecules and reactions, short of wading through papers by hand.

"CAS is very important," says Chris Reed, an inorganic chemist at the University of California, Riverside. ${ }^{\alpha} \mathrm{My}$ students use it all the time, for mining the literature or finding the compounds they want."
PubChem, a free database launched by the US National Institutes of Health (NIH) last September, threatens CAS's monopoly. It is smaller, containing 650,000 molecules so far compared with CAS's 25 million. And it is aimed more at biologists, linking to information such as gene sequences, and related papers in the NIH's PubMed archive of biomedical journals.

\section{0,000 and rising}

But it is growing. On 25 May, records were added from NMRShiftDB, a database of chemicals' nuclear magnetic resonance spectra, and from Nature Chemical Biology, which requires all authors to submit their data to PubChem. Other sources are likely to follow.

The ACS argues that projects that compete with the private sector are a waste of taxpayers' money. The database generates the lion's share of the non-profit ACS's income of $\$ 375$ million, which pays for the society's publications, meetings and staff.

So the society is trying to persuade Congress to make the NIH restrict its database to molecules found by NIH researchers.

Steve Bryant, project director for PubChem, says that's unfair, because the linked content provided by the two databases is different, and they serve different audiences.
Bob Massie, head of CAS, disagrees. "We have been hearing that every chemical researcher understands that PubChem is a substitute for CAS, ${ }^{x}$ he says.

To try to limit PubChem to information produced by NIH researchers, the ACS has been working with lawmakers in Ohio, where CAS employs almost 1,300 people. In particular, it has lobbied congressman Ralph Regula (Republican, Ohio), the chairman of the appropriations subcommittee that allocates money to the NIH.

The society's efforts have intensified ahead of this week's expected debut of the 2006 House Appropriations bill that outlines the agency's proposed budget. As Nature went to press, the draft bill was due on 9 June. An official report accompanying the bill was expected to ask the NIH to limit PubChem to data produced by its own efforts. The report is not legally binding, but if the bill is passed it would be difficult for the NIH to ignore.

Although many chemists are unaware of the ACS's attempt to restrict PubChem, weblogs and library discussion groups have picked up the subject. The fight is turning sour. ${ }^{\alpha} \mathrm{My}$ only interpretation of the ACS's recent actions is that it is no longer trying to represent the best interests of the scientists who form its

\title{
One in three scientists confesses to having sinned
}

More than a third of US scientists, in a survey of thousands, have admitted to misbehaving in the past three years. The social scientists who carried out the study of research misconduct warn that because attention is focused on high-profile, serious cases, a broader threat from more minor deeds is being missed.

Their conclusions may hit a nerve, particularly among scientific societies in the United States. Throughout the 1990s, these groups fought to limit their government's definition of misconduct and the types of behaviour it is responsible for policing.

Brian Martinson of the HealthPartners Research Foundation in Minneapolis, Minnesota, and his colleagues mailed an anonymous survey to thousands of

scientists funded by the National Institutes of Health. They asked the scientists whether they were guilty of misbehaviours ranging from falsifying data to inadequate record keeping.

Of 3,247 early- and mid-career researchers who responded, less than $1.5 \%$ admitted to falsification or plagiarism, the most serious types of misconduct listed. But $15.5 \%$ said they had changed the design, methodology or results of a study in response to pressure from a funding source; $12.5 \%$ admitted overlooking others' use of flawed data; and $7.6 \%$ said they had circumvented minor aspects of requirements regarding the use of human subjects (see page 737).

Overall, about a third admitted to at least one of the ten most serious offences on

"The majority of
misbehaviours reported
are more corrosive than
explosive. That makes
them no less damaging."
the list - a range of misbehaviours described by the authors as "striking in its breadth and prevalence".

But Arthur Caplan, director of the Center for Bioethics at the University

of Pennsylvania, Philadelphia, cautions against concluding that the structure of science is corroded. He points out that dropping an outlying data point is not the same as plagiarizing a paper. 


\section{IMAGE \\ UNAVAILABLE FOR COPYRIGHT REASONS}

Pricing structure: the American Chemical Society makes much of its money selling molecular data.

membership," says Richard Roberts, a chemist at New England Biolabs in Beverly, Massachusetts, and 1993 Nobel laureate, who advises

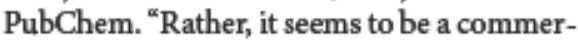
cial enterprise whose principal objective is to accumulate money." To protest, he has pulled out of an upcoming ACS conference in India.
Roberts and the NIH are spreading misinformation, responds Madeleine Jacobs, executive director of the ACS. She complains that NIH staffers have implied that the ACS is trying to shut PubChem down. "We do not and never have opposed the concept of publishing data generated by NIH grantees," she says.
다 “ But what we are seeing now goes far beyond what the NIH first proposed."

Jacobs points out that most of the money < raised from CAS goes towards the society's publishing services, and that these would be jeopardized if profits fell. ACS members she has spoken to agree that PubChem is a waste of public money, she adds.

\section{Offshore option}

Not everyone agrees. "Most of the members I've spoken to are kind of upset about it," says Reed. He is drafting a letter to Chemical of Engineering News, an ACS publication, to complain about the society's actions. Although he doesn't use PubChem himself, he objects to any attempt to squash it. "I can understand the society being nervous about competition, but I think something that is complementary and even a bit competitive is healthy."

He says that he and his colleagues would like to see the ACS be "more forward and innovative in opening access to databases and literature ${ }^{n}$. The University of California is disseminating information on the quarrel to its chemists, along with suggestions for action, and Regula's phone number.

Meanwhile, a group of European chemists, including Peter Murray Rust of the University of Cambridge, UK, is taking a different approach. Worried that researchers elsewhere would lose out if information is removed from the NIH site, they are discussing setting up a European-funded mirror of the site with PubChem, which the US government would have no power to restrict.

Emma Marris
"I don't mean to say that the problems identified don't merit deliberation and a response," he says. "But there may be a tendency if you just read the headlines to say, 'Oh my goodness, the ethical house of science is collapsing around us'."

Martinson counters that, although individual cases may not be as serious as fraud, the survey reveals a threat to the integrity of science that is not captured by narrow definitions of misconduct. "The majority of misbehaviours reported to us are more corrosive than explosive," he says. "That makes them no less damaging."

He thinks the main cause of all the questionable behaviour is the increasing pressure that scientists are under as they compete to publish papers and win grants.
"We need to think about the working conditions in science that can be addressed," he says, suggesting better salaries and employment conditions for young scientists, and a more transparent peerreview process.

He is at pains to stress that he does not think governments should expand regulation of scientific behaviour. And when it was shown Martinson's study, the Federation of American Societies for Experimental Biology, based in Bethesda, Maryland, was quick to reiterate its support for the narrow definition of misconduct that was officially agreed in $\mathbf{2 0 0 0}$.

“The US government adopted 'fabrication, falsification and plagiarism' as the defining criteria, a policy with which we concur," says Paul Kincade, the federation's president. That means the government cannot investigate or punish any behaviours outside that definition.

In 2002, scientific societies led by the federation and the Washington-based Association of American Medical Colleges fought a government office's plan to collect data on such behaviours (see Nature 420, $739-740 ; 2002$ ). The societies argued such monitoring should be the responsibility of scientists themselves.

Martinson and his colleagues say their study is the first attempt to quantify such activities. They hope their results will persuade scientists to stop ignoring the wider range of misbehaviour.

Meredith Wadman 